\section{Optimisation of outpatient resource utilisation in cataract management}

\begin{abstract}
Purpose We assessed whether patients referred with a diagnosis of cataract require outpatient assessment before listing for surgery or whether the general practitioner could have direct access to the waiting list. We also studied whether pre-assessment clinics made a significant difference to management even when waiting times were long.

Methods Data about patients referred with a diagnosis of cataract to the Oxford Eye Hospital and associated hospitals were collected. Seventy-five patients were prospectively studied and $\mathbf{1 0 0}$ patient records were retrospectively analysed.

Results Twenty-six per cent of patients had a misdiagnosis or additional problems affecting management. Optometrists provided more information than general practitioners, but their diagnostic accuracy was equal $(73 \%$ optometrists, $75 \%$ general practitioners). At the pre-assessment clinic pupil dilatation changed management in only $4 \%$ of patients.

Conclusion Listing patients on the basis of referral letters would be inappropriate in 1 in 4 patients. Pre-assessment clinics rarely picked up a clinically relevant change. Thus if outpatient consultation included a decision on the exact surgical plan including implant power, then pre-assessment clinics may not be necessary.
\end{abstract}

Key words Cataract, Outpatient organisation, Pre-assessment, Referral

It is generally accepted that the main reason for the cataract backlog is limited operating sessions and surgical throughput. Imbalance in, and inefficient use of, resources also contributes to this backlog. ${ }^{1}$ The requirement for cataract surgery is set to increase as more uncovered disease $^{2}$ is diagnosed and the proportion of elderly people in the population increases. Increasing use of modern small-incision cataract surgery techniques has increased the turnover in operating theatres and reduced the demand on medical time for the follow-up of postoperative cataract patients. Surgery is
S. PRASAD, V. TANNER, C.K. PATEL,

P. ROSEN increasingly done on an outpatient basis with good outcomes. ${ }^{3}$ Co-management of the postoperative care after cataract surgery has further reduced the demands on the time of medical staff and has increased efficiency. ${ }^{4}$ Increasing the efficiency with which new referrals with the diagnosis of cataract are handled can streamline outpatient management, leading to further savings in time and costs and freeing medical manpower for other tasks.

The present practice in our unit is that patients referred with a diagnosis of cataract go through the steps outlined in Fig. 1 before they have their surgery. We reviewed this process to provide information that would help to organise the service in a more efficient and streamlined manner. In particular we tried to assess whether all patients referred with a diagnosis of cataract need to be examined before being placed on the waiting list for cataract surgery or whether listing them on the basis of the referral letter was appropriate. Other objectives were to evaluate whether the pre-assessment clinic visit made a difference to the medical and surgical management and whether a 'one-stop' assessment and operation would be feasible.

\section{Method}

The study involved two phases. Phase 1 was a retrospective review from case notes of 100 consecutive patients referred with a diagnosis of cataract to a single consultant's (P.R.) firm from 1 April 1995. Phase 2 was a prospective study of 75 consecutive patients referred with the diagnosis of cataract to the same firm from September 1996.

A large number of referrals are initiated by opticians, ${ }^{5}$ whilst others are initiated by the patient's general practitioner (GP). Information provided on the initial referral letter was collected and analysed. Changes in management plan at the pre-assessment clinic were also recorded.

\footnotetext{
S. Prasad

V. Tanner

C.K. Patel

P. Rosen

Oxford Eye Hospital Radcliffe Infirmary Oxford OX2 6HE, UK

S. Prasad $\bullet$ Arrowe Park Hospital Arrowe Park Road Wirral

Merseyside L49 5PE, UK
} 


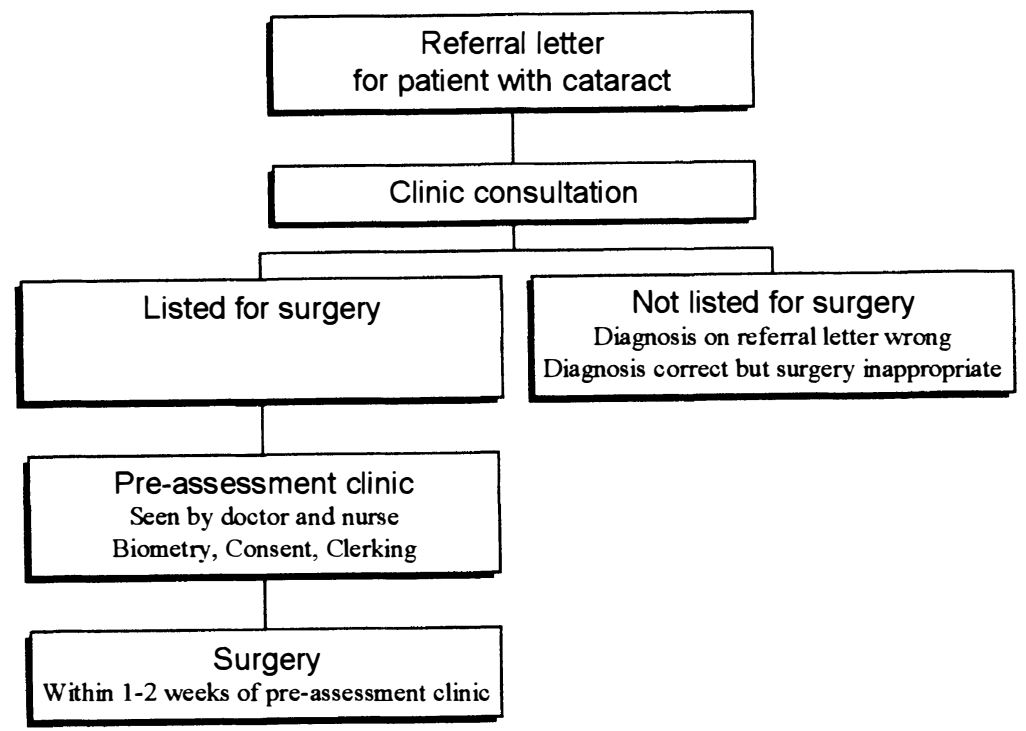

Fig. 1. Flow diagram showing present scheme of management of patients referred with a diagnosis of cataract.

\section{Data collection}

Data were collected and recorded on a data collection sheet in both phases of the study (Fig. 2).

\section{Results}

The results of the review of referral letters and outpatient consultation are set out in Table 1. On combining the

\begin{tabular}{|c|c|c|c|c|}
\hline \multicolumn{5}{|c|}{$\frac{\text { CATARACT REFERRAL AND PRE-ASSESSMENT STUDY }}{\text { Patient Sticker / ID }}$} \\
\hline \multicolumn{5}{|l|}{ 1. Referral and clinic consultation } \\
\hline \multicolumn{2}{|l|}{ Referral initiated by } & \multicolumn{2}{|l|}{ GP } & $\begin{array}{c}\text { Optician } \\
\text { (through GP) }\end{array}$ \\
\hline \multicolumn{2}{|l|}{ Diagnosis of cataract } & \multicolumn{2}{|c|}{ Correct / Incorrect } & Correct / Incorrect \\
\hline \multicolumn{2}{|l|}{ Diagnosis correct but not requiring surgery } & & & \\
\hline \multicolumn{2}{|l|}{$\begin{array}{l}\text { Additional problems recorded at outpatient } \\
\text { clinic (but not mentioned in referral letter) }\end{array}$} & \multicolumn{2}{|l|}{$\begin{array}{ll}\text { - } & \text { Glaucoma } \\
\text { - } & \text { Diabetic } \\
\text { - } & \text { BP } \\
\text { - Other... }\end{array}$} & $\begin{array}{ll}\text { - } & \text { Glaucoma } \\
\text { - } & \text { Diabetic } \\
\text { - } & \text { BP } \\
\text { - } & \text { Other... }\end{array}$ \\
\hline \multicolumn{2}{|l|}{$\begin{array}{l}\text { Further Ophthalmic information provided } \\
\text { by referrer }\end{array}$} & \multicolumn{2}{|l|}{$\begin{array}{ll}\text { - } & \text { VA } \\
\text { - } & \text { IOP } \\
\text { - } & \text { Fundus } \\
\text { - } & \text { Dilated } \\
\text { - } & \text { Other... }\end{array}$} & $\begin{array}{ll} & \text { VA } \\
\text { - } & \text { IOP } \\
\text { - } & \text { Fundus } \\
\text { - } & \text { Dilated } \\
\text { - } & \text { Other... }\end{array}$ \\
\hline \multicolumn{5}{|l|}{ 2. Pre-assessment clinic } \\
\hline Operation cancelled or postponed & & YES & & NO \\
\hline If YES, & $\begin{array}{l}\text { Inap } \\
\text { listi }\end{array}$ & $\begin{array}{l}\text { ppropriate } \\
\text { ng }\end{array}$ & $\begin{array}{l}\text { Furth } \\
\text { befor }\end{array}$ & $\begin{array}{l}\text { r intervention needed } \\
\text { surgery }\end{array}$ \\
\hline $\begin{array}{l}\text { If YES, could the problem have been } \\
\text { picked up at initial (out patient) } \\
\text { consultation }\end{array}$ & & YES & & NO \\
\hline $\begin{array}{l}\text { Management plan altered as a result of } \\
\text { pupil dilatation at this stage }\end{array}$ & & YES & & NO \\
\hline
\end{tabular}

Fig. 2. Data collection sheet used in the study. 
Table 1. Results from assessment letters and outpatient clinic consultation

\begin{tabular}{|c|c|c|c|c|}
\hline & \multicolumn{2}{|c|}{ Phase $1(n=100)$} & \multicolumn{2}{|c|}{ Phase $2(n=75)$} \\
\hline & GP $(n=38)$ & Optician $(n=62)$ & GP $(n=27)$ & Optician $(n=48)$ \\
\hline Diagnosis correct & $32(84 \%)$ & $52(84 \%)$ & $23(85 \%)$ & $41(85 \%)$ \\
\hline Diagnosis correct but surgery inappropriate & $3(8 \%)$ & $8(13 \%)$ & $2(7 \%)$ & $7(15 \%)$ \\
\hline \multirow[t]{3}{*}{ Additional problems noted at OPD } & Glaucoma 2 & Glaucoma 1 & Glaucoma 1 & Glaucoma 1 \\
\hline & Diabetes 2 & Others $8^{c}$ & Diabetic 1 & Others $4^{\mathrm{e}}$ \\
\hline & Others $3^{\mathrm{b}}$ & & Others $1^{\mathrm{d}}$ & \\
\hline \multirow[t]{5}{*}{ Further information provided } & VA $4(10 \%)$ & VA 60 (97\%) & VA $2(7 \%)$ & VA $47(98 \%)$ \\
\hline & IOP 0 & IOP $37(60 \%)$ & IOP 0 & IOP $30(63 \%)$ \\
\hline & Fundus 0 & Fundus $33(53 \%)$ & Fundus 0 & Fundus $29(60 \%)$ \\
\hline & Dilated 0 & Dilated $5(8 \%)$ & Dilated 0 & Dilated $5(10 \%)$ \\
\hline & Fields 0 & Fields $13(21 \%)$ & Fields 0 & Fields $7(15 \%)$ \\
\hline
\end{tabular}

BRVO, branch retinal vein occlusion; CRVO, central retinal vein occlusion; ARMD, age-related macular degeneration; VA, visual acuity; IOP, intraocular pressure.

ablood pressure was not recorded at the outpatient consultation.

${ }^{\mathrm{b}}$ Consisting of one patient each with a pterygium, BRVO and ARMD.

c Consisting of two patients each with BRVO, blepharitis and ARMD and one patient with a choroidal naevus.

${ }^{\mathrm{d}} \mathrm{ARMD}$

e Consisting of one patient each with BRVO and blepharitis and two patients with ARMD.

results of both phases of the study GPs were found to make the diagnosis correctly in $83 \%(54 / 65)$ of cases referred with the diagnosis of cataract. For opticianinitiated referrals $85 \%(93 / 110)$ had the correct diagnosis. However, on excluding the cases in which, at outpatient consultation, surgery was deemed not to be required or inappropriate, the figure falls to $75 \%(49 / 65)$ for GPinitiated referrals and $73 \%(80 / 110)$ of optician-initiated referrals. This indicates that $26 \%(46 / 175)$ of new patients, referred with a diagnosis of cataract, were not placed on the cataract surgery waiting list at their initial outpatient consultation. Additional ocular problems were picked up in $14 \%(24 / 175)$.

Opticians tend to provide more information than GPs when initiating referrals. Visual acuities were mentioned in $97 \%$ of cases by opticians but only $9 \%$ of cases by general practitioners. Opticians also provided information on intraocular pressures (61\%), fundi (56\%) and fields (18\%). GPs tended not to provide additional ophthalmic information.

Table 2 gives the results of the review of the preassessment clinic. Twelve per cent $(18 / 110)$ of patients had their operation cancelled or postponed at the preassessment clinic. The main cause for this was uncontrolled hypertension $(67 \%, 12 / 18)$. The other causes for cancellation of surgery could all have been picked up at the initial outpatient consultation, although progression of the condition from initial consultation to pre-assessment clinic visit could not be ruled out. If the patient did not report a change in symptoms over this time period we presumed that no progression of pathology had taken place. All other causes for postponement or cancellation of surgery at the preassessment clinic comprised $5 \%$ of the patients attending for pre-assessment. Pupil dilatation at the pre-assessment clinic changed the management plan in $4 \%(4 / 110)$ of patients only.

\section{Discussion}

Rapid changes are occurring in healthcare today. Healthcare organisations are being prompted to explore and implement systems that will enhance quality of care as well as promoting cost-effective resource utilisation. ${ }^{6}$ Day case surgery ${ }^{7}$ and co-managed post-operative care ${ }^{4}$ have rationalised resource utilisation during and after surgery. Further increases in efficiency will result from improving referral patterns and pre-assessment.

The review of referral letters and outpatient consultation shows that the diagnostic accuracy of opticians and GPs for cataracts is approximately equal. Seventy-three per cent of referrals initiated by opticians and $75 \%$ of those initiated by GPs were listed for cataract surgery at their initial outpatient consultation. Overall $25 \%$ of patients referred by GPs and $27 \%$ of those patients whose referral was initiated by opticians would benefit from outpatient consultation prior to listing. Opticians tend to obtain and pass on more information

Table 2. Results from the pre-assessment clinic

\begin{tabular}{|c|c|c|}
\hline & Phae $1(n=96)$ & Phase $2(n=54)$ \\
\hline Operation cancelled or postponed & $12(13 \%)$ & $6(11 \%)$ \\
\hline Inappropriate listing & 3 (1 BRVO, 2 ARMD) & 1 (ARMD) \\
\hline Further intervention & 9 (7 BP, 2 blepharitis) & $5(\mathrm{BP})$ \\
\hline Reason should have been picked up at outpatient consultation & All (? except 2 blepharitis) & All \\
\hline Management altered as a result of pupil dilatation at this stage & 3 (1 BRVO, 2 ARMD) & $1(\mathrm{BRVO})$ \\
\hline
\end{tabular}

Note: Numbers are smaller than in Table 1 in both phases as some patients who had had their outpatient consultation had not come to the pre-assesment clinic by the end of the study.

BRVO, branch retinal vein occlusion; ARMD, age-related macular degeneration; BP, high blood pressure. 


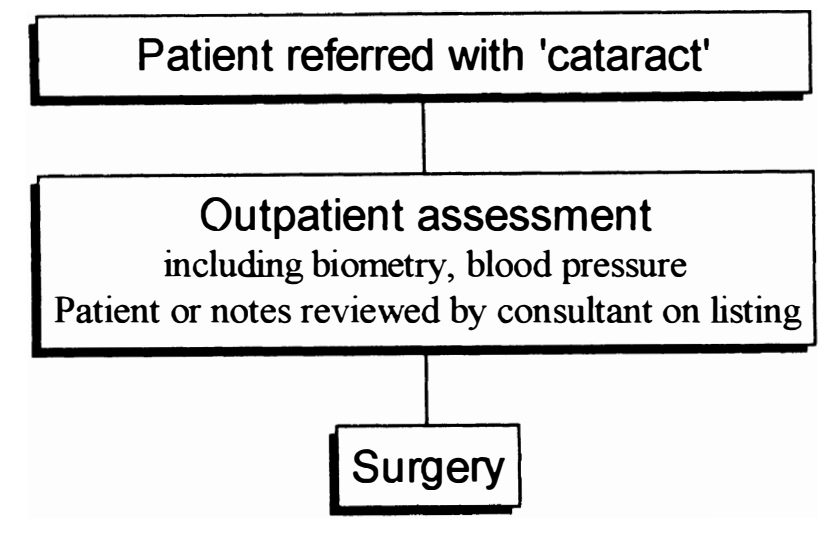

Fig. 3. Proposed scheme of management of patients with a diagnosis of cataract.

about the patient's ophthalmic condition, but this does not seem to improve their overall diagnostic accuracy. As 1 in 4 patients referred with a diagnosis of cataract do not go on to surgery at that episode, a one-stop assessment and operation would not be viable.

It has been shown that a large proportion of optometrists inform their patients about cataract and its management. ${ }^{8} \mathrm{GPs}^{\prime}$ awareness about cataract surgery techniques tends to vary. ${ }^{9}$ The diagnostic accuracy of the referrer would have to be improved before a 'one-stop' assessment and operation became feasible or they could be allowed direct access to the waiting list. Other issues that need to be considered before allowing GPs direct access to waiting lists include a loss of control and possible revenue implications.

The commonest problem for postponement of surgery at the pre-assessment clinic was uncontrolled hypertension. This clinic made a difference to the management of only $5 \%$ of patients if uncontrolled hypertension was excluded. Dilating pupils at the preassessment clinic affected the management of $4 \%$ of patients only. Checking the blood pressure of all new referrals at their initial consultation and application of more stringent criteria for listing can increase the usefulness of this consultation. This would avoid inappropriate listing. If the initial consultation were to include biometry and decision on implant power, preassessment clinics would have little to add to patient management. Currently, only $20 \%$ of cataracts are done on a day-case basis in our unit. This is mainly due to social and transport problems. It is reasonable to assume that similar problems apply to visiting the hospital for pre-assessment. Patients seem to like pre-assessment clinics as they give them an opportunity to get more information about the procedure. This can be addressed in other ways, such as providing a video of relevant information supplemented by a postal questionnaire or a phone call by the pre-assessment nurse to confirm social circumstances. Eliminating the need for pre-assessment clinics would lead to savings in patient time, reduced inconvenience, a cut in transport costs and a freeing of medical manpower.

\section{Conclusion}

An improved scheme of organising outpatient services for cataract patients is shown in Fig. 3. This would result in more efficient utilisation of resources and streamline patient turnover, resulting in savings in terms of time, patient inconvenience and demands on the time of medical staff.

\section{References}

1. Drummond MF, Yates JM. Clearing the cataract backlog in a (not so) developing country. Eye 1991;5:481-6.

2. Wormald RP, Wright LA, Courtney P, Beumont B, Haines AP. Visual problems in the elderly population and implications for services. BMJ 1992;304:1226-9.

3. Olsen T, Bargum R. Outcome monitoring in cataract surgery. Acta Ophthalmol Scand 1995;73:433-7.

4. Revicki DA, Brown RE, Adler MA. Patient outcomes with comanaged post-operative care after cataract surgery. J Clin Epidemiol 1993;46:5-15.

5. Port MJ, Pope CA. Referrals and notifications by British optometrists. Ophthalmic Physiol Optics 1988;8:323-6.

6. MacKenzie M, Waterman M. Utilization of a clinical pathway in the care of the ambulatory cataract surgical patient. Insight 1995;20:6-11.

7. Hylka SC. Comparative cost analysis of surgical procedures in an ambulatory eye center. Nursing Econ 1994;12:51-5.

8. Bezan D. Management of patients with age-related cataracts: a survey of Oklahoma optometrists. J Am Opt Assoc 1987;58:100-4.

9. Potamitis T, Fouladi M, Aggarwal RK, Jones HS, Fielder AR. General practitioners' awareness of different techniques of cataract surgery: implications for quality of care. BMJ 1994;308:1334-5. 